\title{
Acceptance of Smart Phone by Younger Consumers in Malaysia
}

\author{
Yong Hoe Hong ${ }^{1}$, Boon Heng Teh ${ }^{1} \&$ Chin Hooi Soh ${ }^{1}$ \\ ${ }^{1}$ Faculty of Management, Multimedia University, Cyberjaya, Malaysia \\ Correspondence: Yong Hoe Hong, Faculty of Management, Multimedia University, 63100 Cyberjaya, Malaysia. \\ E-mail: yhhong@mmu.edu.my
}

\author{
Received: October 18, 2013 Accepted: January 13, 2014 Online Published: February 26, 2014 \\ doi:10.5539/ass.v10n6p34 \\ URL: http://dx.doi.org/10.5539/ass.v10n6p34
}

\begin{abstract}
The sales of smart phone are rapidly increasing in Malaysia and in the global markets. Which means that, smart phone has a great opportunity in the future growth of the mobile industry. The aim of this research is to determine the acceptance of smart phone by younger consumers in Malaysia. A total of 113 useable questionnaires was collected and analyzed through SPSS. Google doc form was utilized to create the online questionnaire. The data collection method utilized in this paper was online interview. The result shows that, perceived usefulness (PU), perceived ease of use (PEOU), and Internet self-efficacy (ISE) significantly influenced the acceptance of smart phone by younger consumers in Malaysia. However, no relationship exists among Internet self-efficacy, perceived usefulness and perceived ease of use. Future studies should explore more on other factors to determine the acceptance of smart phone.
\end{abstract}

Keywords: acceptance, smart phone, Internet self-efficacy, perceived ease of use, perceived usefulness

\section{Introduction}

The smart phone is a phone provides more functions and applications than standard phones. According to the Euro Monitor International (2012), the number of smart phone sales in Malaysia was 2,499,800 units in 2011, which was equivalent to $38 \%$ growth. The most popular operating system for smart phone (retail volume) in Malaysia is Android (53\%), followed by iOS (23\%), Windows (10\%), and Blackberry OS (8\%). The smart phone is more than a mere communication too. The smart phone is also for social networking, surfing, searching online information, and others. In the future, a smart phone can be a very powerful communication tool for every human being. The sales of mobile phones in the global market decreased for the first time last year since 2009 . However, the sales of smart phone are increasing rapidly in the global market and this situation is expected to continue for another few years (The Star, 2013). In 2012, Samsung was the global leader in the smart phone market followed by Apple (Euro Monitor International, 2013). Sarwar \& Soomro (2013), conducted a research on the positive and negative impacts of smart phone on business, education, health, and psychological. The findings of the research clearly stated that smart phone have created a huge impacts on the lifestyle of a society. "Nomophobia" is a psychological syndrome, which refers to a mobile phone user who is worried about having no mobile phone especially smart phone in their daily life. According to Gadgets Home (2013), a survey conducted by Cisco in Australia showed that nine out of 10 respondents under the age of 30 were worried about losing their phone and are addicted to their smart phones. This phenomenon has caused wide concerned from parents and the society

Global brand continues to dominate the smart phone market in Malaysia. Local brands such as CSL and others only captured less than 5\% the market share. According to Euro Monitor International (2012), local brands lacks of innovation and resources. This situation places local brand in a poor position to compete with global brands. Euro Monitor International (2012) also predicted that smart phone sales in Malaysia will reach 3,181,000 units in $2013,3,566,100$ units in 2014, and 3,406,430 units in 2015. This finding shows that, smart phone has a great opportunity for future growth in Malaysia. The addition of more mobile features on a phone will motivate users switching to smart phones in the future.

Gartner predicted that the total money spent on mobile phone entertainment products, services, smart devices and others will reach US\$2.1 trillion in 2013 (The Star, 2013). However, limited studies have been conducted about the acceptance of smart phone in Malaysia. Researchers have demonstrated interest in the study of smart phones. Previous studies mainly focus on the older consumer segment especially in healthcare and logistics 
industries (Park \& Chen, 2007; Chen et al., 2010; Putzer \& Park, 2010). This study focuses on a younger consumer segment in the education industry. Younger consumer segments are becoming one of the important segments in the smart phone market in Malaysia. Several studies have proven that younger consumers have a great buying power and high willingness to accept or adapt to a new technology especially smart phone. This study determines the factors that influence the acceptance of smart phone by younger consumers in Malaysia.

\section{Literature Review}

\subsection{Technology Acceptance Model (TAM)}

The technology acceptance model (TAM) developed by Davis (1989) was adapted from the theory of reasoned action (Ajzen \& Fishbein, 1975). TAM was applied to acceptance or adoption of smart phone by few researchers (such as Park \& Chen, 2007; Cheng et al., 2009; Kim \& Zhang, 2009; Verkasalo et al., 2009; Kang et al., 2011; Bouwman et al., 2012; Fahad, 2012). TAM comprised two measurable determinants for technology product or system acceptance namely perceived usefulness (PU) and perceived ease to use (PEOU). These two determinants are strongly related to the attitude towards the use and behavioral intention of a particular technology product or system. These determinants are significant in the acceptance of a particular technology product or system.

\subsection{Conceptual Framework}

Figure 1 shows the conceptual framework of this research, which was adapted from the technology acceptance model. TAM is widely utilized in studies on acceptance of a new technology or services. However, TAM remains the best models used by many researchers. Aldhaban (2012) mentioned that TAM is the most popular study model among the researchers compared with unified theory of acceptance and use of technology (UTAUT), diffusion of innovation (DIT), theory of reasoned action (TRA), and innovation of diffusion theory (IDT).

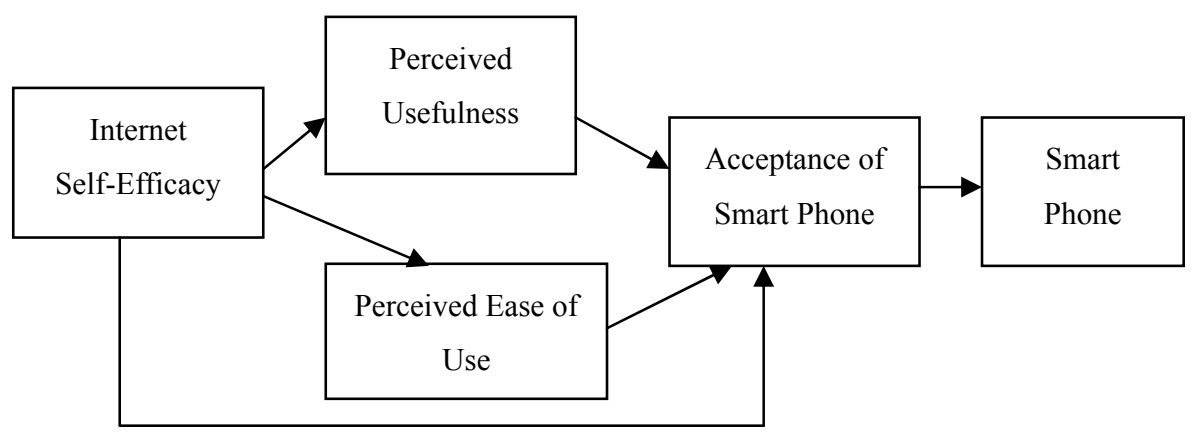

Figure 1. Conceptual framework

\subsection{Perceived Usefulness (PU) and Perceived Ease of Use (PEOU)}

Convenience factors, social needs, and influences were the factors that influenced the dependency of students on smart phones. A positive relationship exists between the dependency of students on smart phones and their purchase behavior in the future (Ting et al., 1999). Chan and $\mathrm{Lu}$ (2004) investigated Internet banking adoption and use behavior in Hong Kong. The research model was based on the technology acceptance model (TAM2) and social cognitive theory. The intention to adopt or use Internet banking was not significantly affected by the perceived ease to use. However, the perceived usefulness significantly affects the intention to adopt or use Internet banking. The conceptual model of this study was adapted from TAM (Eriksson et al., 2005). This model shows that usage behaviors are depend on the subject's intention to use, perceived usefulness, and perceived ease to use. The findings showed that the usage of Internet banking is significantly affected by perceived usefulness but not by perceived ease to use. PEOU has a positive effect on PU.

Park \& Chen (2007) investigated the adoption decision of medical doctors and nurses by utilizing the TAM. This study showed that PEOU and PU were positively related to the attitude toward using smart phones. Kim (2008) conducted a study to determine the adoption of a smart phone by adding two new constructs to the existing TAM. These two constructs are perceived cost savings (PCSs) and the company's willingness to fund (CWF). Job relevance and experience were added as moderating factors. The factors in this study were significantly related to the adoption of a smart phone. According to Lee at al. (2009), their research was to determine the impact of lifestyles on the adoption of high-technology products. The research model used in this research was based on TAM. The findings show that consumer lifestyles were strongly affected by the adoption of high-technology 
products. A strong relationship existed between lifestyles and intention to adopt. Chen et al. (2010), examined the acceptance of smart phones in the healthcare industry by utilized the TAM. The findings confirmed that self-efficacy, PEOU, and PU were significantly influenced by consumers' attitude toward using smart phones. Putzer \& Park (2010) investigated the effects of the innovation factors to determine the smart phone adoption among nurses in the Southeastern community hospitals in the United States. Five innovation factors are used in this study, namely, observability, compatibility, job relevance, internal environment, and external environment. These factors significantly affected consumers' attitude towards the adoption of a smart phone. Bouwman et al. (2012) published a study on adoption of advanced mobile services in Holland. The theoretical framework for this study was adapted from TAM. The results demonstrated that PU, PEOU, and attitudes positively affected the adoption of advanced mobile services. Thus, the following hypotheses are suggested:

H1: A relationship exists between PU and acceptance of a smart phone

$\mathrm{H} 2$ : A relationship exists between PEOU and acceptance of a smart phone

\subsection{Internet Self-Efficacy (ISE)}

The main difference between a smart phone and a mobile phone is that a smart phone requires Internet to perform certain functions. This study strongly believes that, ISE influences PEOU, PU, and acceptance of smart phones.

Wang et al. (2003) employed an empirical cross-sectional survey in Taiwan. The theoretical model for this study was based on TAM (Davis, 1989). Two new variables were added, namely: computer self-efficacy and perceived credibility. The findings indicated that computer self-efficacy has a significant effect on the acceptance of the user's towards acceptance of Internet banking through perceived usefulness, perceived ease of use, and perceived credibility. The result also showed that perceived ease of use has a strong influence on behavioral intention than perceived usefulness. Lassar et al. (2005) conducted a study to explore the relationships between consumer innovatiness, self-efficacy on the Internet, Internet attitudes, and online banking adoption, while controlled by personal characteristics. This study was integrated the technology acceptance model (TAM) and the adoption of innovation framework to develop predictions of online banking acceptance. The results show that the Internet self-efficacy was significantly related to online banking.

Eastin \& LaRose (2000), Internet self-efficacy was positive significantly related to prior Internet experience, outcome expectancy, and Internet usage. Besides, eight items of Internet self-efficacy scale were developed in their research. The results showed that the items are reliable and consistent. According to Hsu \& Chiu (2003), self-efficacy in terms of Internet and web-specific strongly affected electronic service acceptance and usage. Internet self-efficacy was a vital factor in the electronic service implementation in Taiwan. Yi \& Hwang (2003) conducted a study to predict the use of web-based information systems by adapting TAM. The additional three motivational variables included in this study are self-efficacy, enjoyment, and learning orientation. These variables significantly affected the intention and use of web-based information systems. However, PEOU was not significantly affected the PU and enjoyment. Torkzadeh et al. (2006) developed 15 questions for Internet self-efficacy based on Torkzadeh \& Van Dyke (2002). This study demonstrated that Internet self-efficacy was significantly influenced by the attitude of the user. Chen et al. (2009), the purpose of the research was to test the four theoretical frameworks including TAM to determine the intention to adopt a smart phone by an employee in a logistics company. The results of this study indicate that the relationship between constructs is not different among the models. However, behavioral intention was strongly affected by self-efficacy. Thus, the following hypotheses are suggested:

H3: A relationship exists between ISE and acceptance of smart phone

H4: A relationship exists between ISE and PU

H5: A relationship exists between ISE and PEOU

\section{Methodology}

The survey approach was chosen in this study because this approach is one of the most practical ways to determine the acceptance of smart phone among young consumers. Smart phone users for at least one year were selected as subjects. The initial sample consisted of 300 postgraduate and undergraduate students and data were collected from 1 to 20 July 2013. A total of 187 participants did not complete and respond to the questionnaire.

The questionnaire in this study is adapted from Kim (2008), Park \& Chen (2007), and Hsu \& Chin (2003). Moreover, the design of the online questionnaire is based on the software programs, which enable the researchers to the development and management of the questionnaires. This approach will help the retrieval and analysis of 
data. The benefits of utilizing an online questionnaire include speed, friendliness, flexibility, and accommodating the standard questions (Burns \& Bush, 2010). Therefore, Google doc form was utilized to create the online questionnaire. The data collection method utilize in this study was online interview, which requires respondents need to answer the questions online. Meanwhile, the statistical analysis techniques used in this study are descriptive, factor, and regression.

\section{Results and Discussion}

\subsection{Descriptive Analysis}

As can be seen from the table 1 , the respondents were between 18-29. The female respondents (56.6\%) outnumbered the male respondents (43.4). The majority of the respondents are an undergraduate $(92 \%)$. About 46.0 percent of the respondents have been using smart phones for 4-6 years, followed by 1-3 years of usage $(42.5 \%)$. This finding shows that the younger generation is beginning to use smart phone at a much earlier age compared with the older generations. This result also indicates that the younger generation is one of the biggest markets for smart phones. Therefore, local brands can develop a smart phone model targeted mainly for this segment. Younger generations are spending 4-6 hours (43.4\%) per day for in smart phone usage, which indicates that that spend most of their time on a smart phone than with their study. This situation will indirectly bring very unhealthy impacts on their lifestyles. A student who spends more time using smart phones than his or her study is hard to imagine.

Table 1. Descriptive analysis

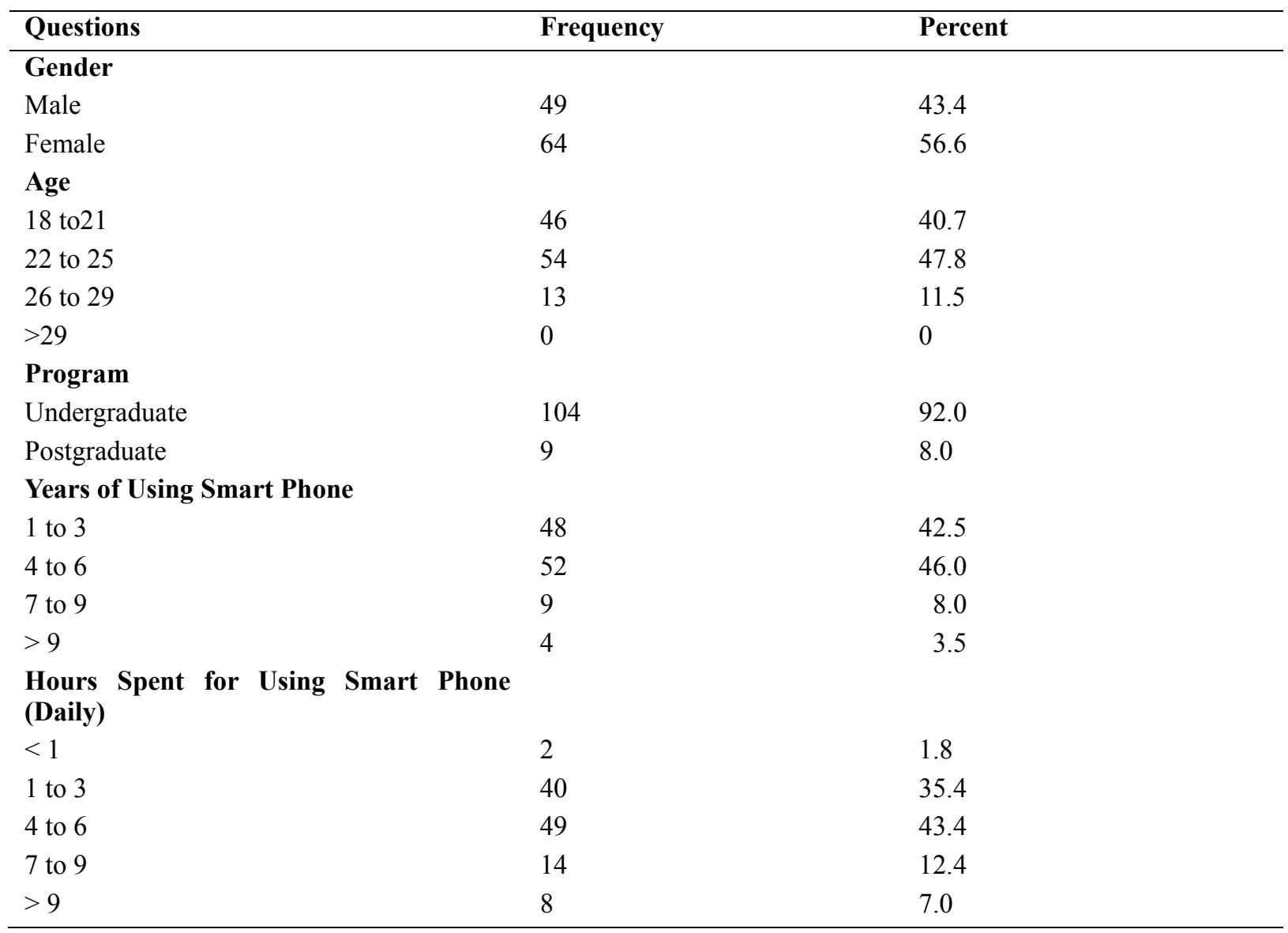

\subsection{Factor Analysis}

Table 2 presents the result obtained from the factor analysis. As can be seen from table 2, all the items in this survey are above 0.5 . That means, these items are acceptable to be analyzed (Malhotra, 2007). 
Table 2. Factor analysis

\begin{tabular}{lll}
\hline Variables & Items & Factor Loading \\
\hline & Useful in my study & 0.729 \\
& Improve my study performance & 0.686 \\
& Complete assignment fastest & 0.673 \\
Perceived Usefulness & Easy to understand and use & 0.679 \\
& Operating system is easy to operate & 0.659 \\
Perceived Ease of Use & Easy to interact with & 0.627 \\
Internet Self-efficacy & Look for web information & 0.524 \\
& Visit the website & 0.534 \\
& Access the email & 0.669 \\
& Connect social networks & 0.601 \\
& Download and upload the files & 0.589 \\
\hline
\end{tabular}

Table 3 shows that the level of significance of PU, PEOU and ISE are 0.01, 0.027 and 0.043 respectively. This result indicates that a relationship among PU, PEOU, ISE and the acceptance of smart phone exist. The findings of this show that PU and PEOU strongly influence the smart phone acceptance. The relationship that exists between PU and acceptance of smart phone is mainly attributed to smart phone users who believe that the use of smart phones will increase their performance. The relationship between PEOU and acceptance of smart phone exist mainly because the smart phone operating system effortless to use. The relationship between ISE and acceptance of smart phone exist attributes to the numerous functions of smart phone. Smart phone can also utilize for social networking, surfing, searching for information, browsing the web, and checking emails. However, hypotheses 4 and 5 are not significant because significance levels are 0.157 and 0.238 respectively. Contrary to the expectations, this study did not find a significant relationship among PEOU, PU, and ISE. This rather contradictory result may be attributed to the lack of ISE on PU and PEOU.

\subsection{Regression Analysis}

Table 3. Regression analysis

\begin{tabular}{llll}
\hline Hypotheses & F-value & t-value & P-value \\
\hline H1 & 1.726 & 13.30 & 0.001 \\
H2 & 1.849 & 9.712 & 0.027 \\
H3 & 1.513 & 7.715 & 0.043 \\
H4 & 0.992 & 5.298 & 0.157 \\
H5 & 0.463 & 3.433 & 0.238 \\
\hline
\end{tabular}

\section{Conclusion}

This study was conducted to determine the factors that influence the acceptance of smart phone by younger consumers in Malaysia. This study found that the acceptance of smart phones is influenced by perceived usefulness, perceived ease of use, and Internet self-efficacy. This study only examined three factors. Therefore, future studies may focus on more factors to determine the acceptance of smart phones in Malaysia.

Local brands should penetrate into global markets instead of focus on Malaysia market only. Millions of people worldwide, especially in Africa are not yet to use smart phones. It shows that global markets are the huge market for smart phone in the future. Therefore, local brands should develop an effective global marketing program to reach these countries.

\section{References}

Aldhaban, F. (2012). Exploring the adoption of smart phone technology: Literature review. Picmet'12 Proceedings: Technology Management for Emerging Technologies, 2758-2770.

Burns, C. A., \& Bush, F. R. (2010). Marketing Research (6th ed.). New Jersey Pearson.

Chan, C. S., \& Lu, T. M. (2004). Understanding internet banking adoption and use behavior: A Hong Kong 
Perspective. Journal of Global Information Management, 12(3),

23. http://dx.doi.org/10.4018/jgim.2004070102

Chen, C. J., Park, Y., \& Putzer, J. G. (2010). An examination of components that increase acceptance of smart phones among healthcare professionals. Electronic Journal of Health Informatics, 5(2), 12.

Chen, V. T., Yen, C. D., \& Chen, C. K. (2009). The acceptance and diffusion of innovation service product use: a case study of delivery Service Company in logistics. Information and Management, 46, $241-248$. http://dx.doi.org/10.1016/j.im.2009.03.001

Eastin, S. M., \& LaRose, R. (2000). Internet self-efficacy and the psychology of the digital divide. Journal of Computer Mediated Communication, 6(1).

Eriksson, K., Kerem, K., \& Nilsson, P. (2005). Customer acceptance of internet banking in Estonia. International Journal of Bank Marketing, 23(2), 200-216. http://dx.doi.org/10.1108/02652320510584412

Hsu, H. M., \& Chiu, M. C. (2003). Internet self-efficacy and electronic service acceptance. Decision Support System, 38, 369-381. http://dx.doi.org/10.1016/j.dss.2003.08.001

Kim, H. S. (2008). Moderating effects of job relevance and experience on mobile wireless technology acceptance: Adoption of a smartphone by individuals. Information and Management, 45, $387-393$. http://dx.doi.org/10.1016/j.im.2008.05.002

Lee, J. H., Lim, J. H., Jolly, D. L., \& Lee, J. C. (2009). Consumer lifestyles and adoption of high-technology products: A case of South Korea. Journal of International Consumer Marketing, 21, 153-167. http://dx.doi.org/10.1080/08961530802153854

Malhotra, K. N. (2008). Marketing Research (5th ed.). New Jersey Pearson.

Mobile phones in Malaysia. (2013). Euro monitor International.

Nine out of 10 suffering from 'nomophobia', fear of having no mobile phone. (2013). Gadgets Home.

Park, Y., \& Chen, V. J. (2007). Acceptance and adoption of the innovation use of smart phone. Industrial Management and Data Systems, 107(9), 1349-1365. http://dx.doi.org/10.1108/02635570710834009

People world-wide are buying fewer mobile phones for first time in four years. (2013). The Star.

Pouwman, H., Nicolas, L. C., Castillo, M. J. F., \& Hattum, V. P. (2012). Consumer lifestyles: Alternative adoption patterns for advanced mobile services. International Journal of Mobile Communications, 10(2), 169-189. http://dx.doi.org/10.1504/IJMC.2012.045672

Putzer, J. G., \& Park, Y. (2010). The effects of innovation factors on smart phone adoption among nurses in community hospitals. Research Perspectives in Health Informatics, 7(1b), 12.

Sarwar, M., \& Soomro, R. T. (2013). Impact of smartphone's on society. European Journal of Scientific Research, 98(21), 216-226.

Ting, H. D., Lim, F. S., Patanmacia, S. T., Low, G. C., \& Ker, C. G. (2011). Dependency on smart phone and the impact on purchase behavior, 12(3), 193-203.

Torkzadeh, G., \& Dyke, V. P. T. (2002). Effects of training on internet self-efficacy and computer user attitudes. Computer in Human behavior, 18, 479-494. http://dx.doi.org/10.1016/S0747-5632(02)00010-9

Torkzadeh, G., Chang, J. C., \& Demirhan, D. (2006). A contingency model of computer and internet self-efficacy. Information and Management, 43, 541-550. http://dx.doi.org/10.1016/j.im.2006.02.001

Wang, S. Y., Wang, M. Y., Lin, H. H., \& Tang, I. T. (2003). The relationship between consumer innovatiness, personal characteristics, and online banking adoption. International Journal of Bank Management, 23(2), 176-199.

Yi, Y. M., \& Hwang, J. Y. (2003). Predicting the use of web-based information systems: Self-efficacy, enjoyment, learning goal orientation, and the technology acceptance model. International Journal of Human Computer Studies, 59, 431-449. http://dx.doi.org/10.1016/S1071-5819(03)00114-9

\section{Copyrights}

Copyright for this article is retained by the author(s), with first publication rights granted to the journal.

This is an open-access article distributed under the terms and conditions of the Creative Commons Attribution license (http://creativecommons.org/licenses/by/3.0/). 